\title{
The choice of primary energy source including PV installation for providing electric energy to a public utility building - a case study
}

\author{
Bartosz Radomski ${ }^{1,}$, Barbara Ćwiek $^{1}$, Tomasz M. Mróz ${ }^{1}$ \\ ${ }^{1}$ Poznań University of Technology, Institute of Environmental Engineering, Piotrowo 3a, 60-965 \\ Poznań, Poland
}

\begin{abstract}
The paper presents multicriteria decision aid analysis of the choice of PV installation providing electric energy to a public utility building. From the energy management point of view electricity obtained by solar radiation has become crucial renewable energy source. Application of PV installations may occur a profitable solution from energy, economic and ecologic point of view for both existing and newly erected buildings. Featured variants of PV installations have been assessed by multicriteria analysis based on ANP (Analytic Network Process) method. Technical, economical, energy and environmental criteria have been identified as main decision criteria. Defined set of decision criteria has an open character and can be modified in the dialog process between the decision-maker and the expert - in the present case, an expert in planning of development of energy supply systems. The proposed approach has been used to evaluate three variants of PV installation acceptable for existing educational building located in Poznań, Poland the building of Faculty of Chemical Technology, Poznan University of Technology. Multi-criteria analysis based on ANP method and the calculation software Super Decisions (C) has proven to be an effective tool for energy planning, leading to the indication of the recommended variant of PV installation in existing and newly erected public buildings. Achieved results show prospects and possibilities of rational renewable energy usage as complex solution to public utility buildings.
\end{abstract}

\section{Selection of a photovoltaic system - a case study}

Due to their simplicity and broad application range, PV systems have become one of the most desirable options to assist the energy balance of the building - green energy. The design of the PV system should cover a number of technical, economic, energy and environmental aspects. Fig. 1. presents the proposed overall algorithm of planning photovoltaic systems, which includes various stages of implementation of the investment.

\footnotetext{
${ }^{*}$ Corresponding author: bartosz.an.radomski@doctorate.put.poznan.pl
} 


\subsection{Selection and rate of location for future investment}

This article shows the result of multi-criteria analysis of the choice of the photovoltaic system for existing building Didactic Centre of the Faculty of Chemical Technology (CDWTCh), located on the Warta Campus at Poznan University of Technology, Poland. The main building entrance is located on the south side, while the north side is the underground car park. Over the east and west side glass façades, 15-meter high racks were installed: one talks of Double Skin Façade (Fig. 2). Their task is to reduce the excessive direct sunlight premises, resulting in increased demand for cooling energy. During the usage of the facility, it turned out that the mounted glass hindered the cleaning process of the windows and the two building facades. What is more, as a result of insufficient transparency of the glass, the interior is not receiving enough daylight. As a result of the complications presented, the idea of replacing the second facade with a useful photovoltaic installation, structurally supported on the existing rack has been considered. Bearing in mind the building location, the area which may take a photovoltaic system, its slope (vertical wall) and the azimuth, there are two rectangle-shaped areas measuring $46 \times 15 \mathrm{~m}$, that can be used for PV panel installation. That would give a total area of nearly $1400 \mathrm{~m}^{2}$.

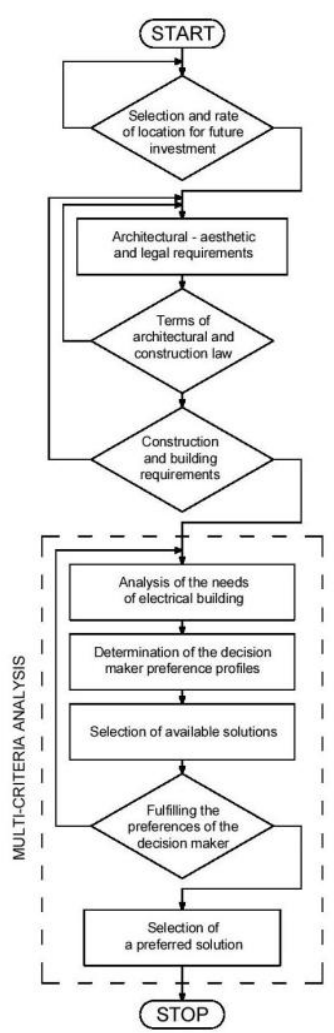

Fig. 1. The general algorithm of planning PV systems.

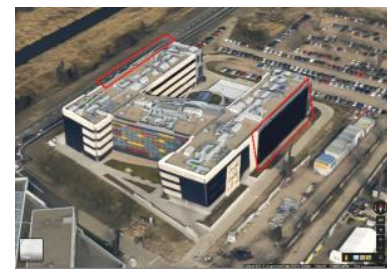

a) North Direction

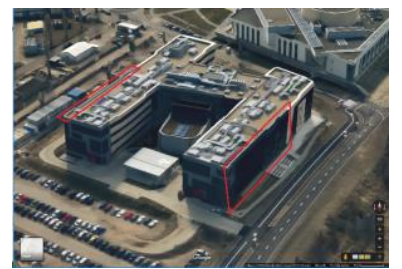

b) South Direction

Fig. 2. Building CDWTCh, satellite photos indicating "Double skin facade".

Google Maps - access 2016-10-08

\subsection{Terms of architectural and construction law}

The fulfilment of the architectural, aesthetic and legal conditions for existing buildings during the construction of the new PV installation may be the biggest challenge. In this paper there are two solutions taken into consideration. The first is based on the body of traditional PV panels, leaving space for windows and the second constitutes a full façade, without voids using PV panels with daylight transparency of approx. $70 \%$. In the case of public buildings, aesthetics can become a key factor and influences the choice of recommended solution. The idea of replacing the existing unfavourable second façade and increasing the profitability of the investment determines the search for solutions that meet the conditions of building construction (usage of existing frames). Hence the choice of specific models of PV panels and their arrangement can vary significantly. 


\subsection{Analysis of the electricity demand of educational building}

The total electricity consumption in the building CDWTCh in 2016 was derived using the BMS monitoring data. An annual electricity consumption profile was created on the basis of collected measurements (Fig. 3.).

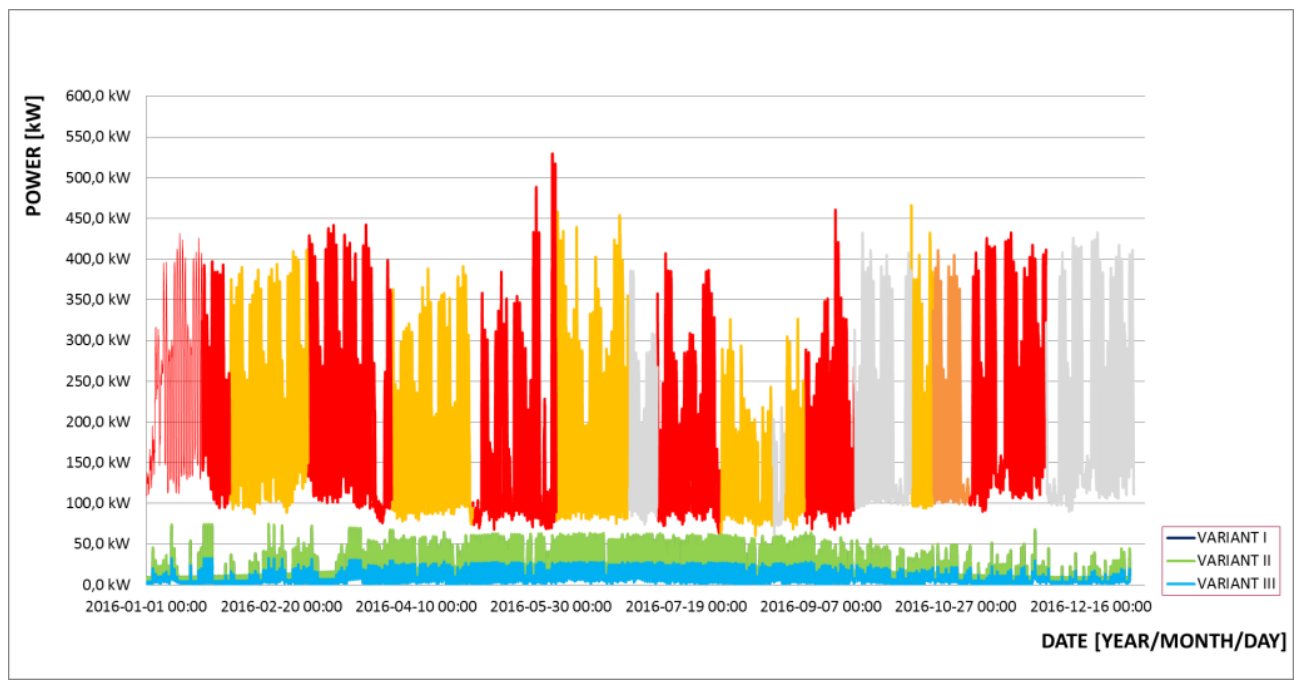

Fig. 3. Annual electricity consumption profile of the building CDWTCh - data from the BMS *

* Periods marked in gray represent an estimate of the value of electricity consumption in the facility, due to the lack of measurements within the prescribed time

The analysis of the electricity consumption in the facility CDWTCh leads to following conclusions:

- daily electrical power needed to supply the building varies according to the season in the range of 70-450 kW for days and within the 70-300 kW during the weekend, while the night-time demand of power is stable throughout the year and varies between $70-100 \mathrm{~kW}$,

- during days off, the mean instantaneous electric power consumed by the building varies from 60 to $100 \mathrm{~kW}$,

- during the year, there are several peaks of power where electric power drawn exceeds the the value of $450 \mathrm{~kW}$,

- the maximum instantaneous electric power reported in the building was $525 \mathrm{~kW}$ (30th May), and the minimum $60 \mathrm{~kW}$ (13th August),

- annual electricity consumption in the building CDWTCh over the year considered was 1 720.3 .

\subsection{Selection of available solutions}

After fulfilling all the necessary conditions to meet the demands of a potential photovoltaic installation and after determining the power demand of the object, an analysis of available market solutions was carried out. On the basis of market research, three variants of photovoltaic panels have been selected.

\section{Variant I - SOLARWORLD SW 260 poly}

The first solution stands out thanks to its lowest price. The maximum power of one module with dimensions of $1675 \times 1001 \times 33 \mathrm{~mm}$ and a weight of $18 \mathrm{~kg}$ is Pmax $=260 \mathrm{Wp}$ (STC 
conditions). Each module has three zones with its own bypass diode, with shady approx. $40 \%$ they are excluded from use. This increases the efficiency of the panels and extends their service life, while minimizing the risk of damage. Within each module there are 60 polycrystalline cells. The set is based on high-quality components, including 8 inverters Fronius SYMO 15,0-3-M.
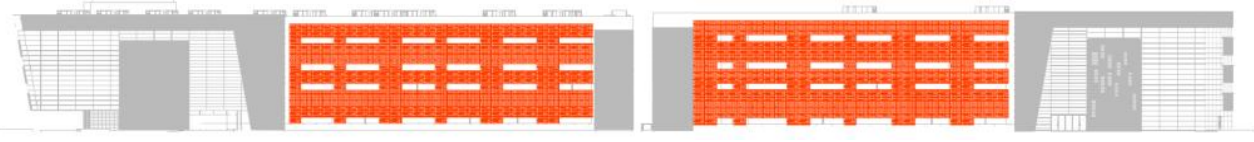

Fig. 4. Design of S-E and N-W facades using SW 260 poly panels.

\section{Variant II - SOLARWORLD SW XL mono}

The second variant is characterized by a high solar to electricity energy conversion efficiency, which can go as high as $\eta=16.3 \%$. A high maximum output of one module Pmax $=325 \mathrm{Wp}$ (STC) can be achieved thanks to its large surface area of monocrystalline cells of $1.77 \mathrm{~m} 2$, with dimensions of $1993 \times 1001 \times 33 \mathrm{~mm}$ and weight $21.6 \mathrm{~kg}$. Each module includes 72 high-performance monocrystalline cells. Just as in Variant I, the product also has 3 bypass diodes. The set is based on high-quality components, including 8 inverters Fronius SYMO 15,0-3-M.
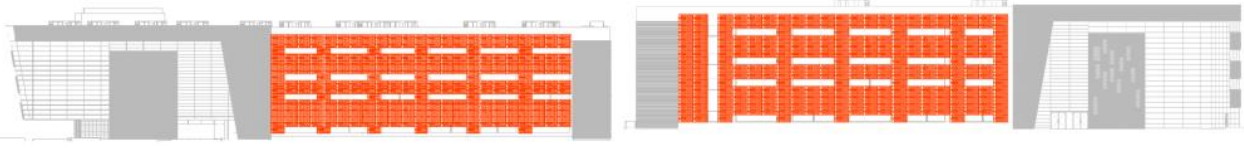

Fig. 5. Design of S-E and N-W facades using SW XL mono panels.

\section{Variant III - MLsystem C60 mono}

The third variant is characterized by a high architectural and practical quality. The structure of photovoltaic panels is designed to achieve the expected transparency, which in this case results in the penetration of sufficient daylight to the rooms overshadowed by second elevation (assuming 74\% transparency). The modules with dimensions of 2400x1000 mm made of tempered glass have 40 monocrystalline cells $(125 \times 125 \mathrm{~mm})$ with a high conversion efficiency of $\eta=23.7 \%$. Despite the high efficiency due to the incomplete coverage of cell modules, a maximum power of a selected module is only Pmax $=138 \mathrm{Wp}$ (STC).
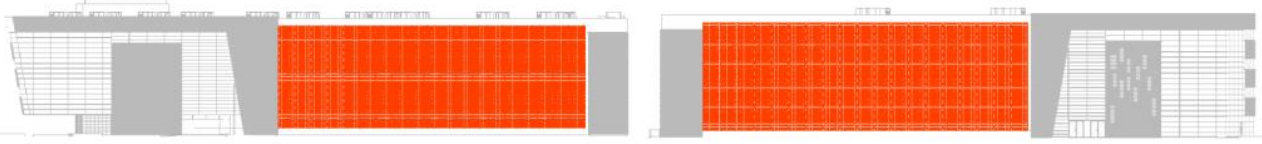

Fig. 6. Design of S-E and N-W-panels facades using MLsystem C60 mono panels.

All three variants considered have their specific advantages: variant I - the lowest investment cost, variant II the largest nominal power and variant III the best aesthetics. Hence, the choice of the recommended variant starts to be the decision problem, which can be solved using multi-criteria decision aid (MCDA) approach.

\subsection{The set of decision criteria}

The choice of the electricity supply variant for a public building depends on a number of technical, economic, energy and environmental factors. For such a defined decision problem, a set of evaluation criteria (features) has been proposed (Tab. 1). A detailed description of the selected evaluation criteria can be found inter alia in $[1,2,5,6]$. 
Table 1. A set of criteria and sub-criteria decision-making for the selection of the power supply of electricity using PV installations with an indication of the preferences and numerical values

\begin{tabular}{|c|c|c|c|c|c|c|c|c|}
\hline \multicolumn{6}{|c|}{ A set of criteria and sub-criteria decision-making } & \multicolumn{3}{|c|}{ Values } \\
\hline Lp. & Criteria & Sub-criteria & Symbol & Unit & $\begin{array}{c}\text { Preferences } \\
\text { direction }\end{array}$ & $\begin{array}{c}\text { Variant } \\
\text { I }\end{array}$ & $\begin{array}{c}\text { Variant } \\
\text { II }\end{array}$ & $\begin{array}{c}\text { Variant } \\
\text { III }\end{array}$ \\
\hline \multirow{3}{*}{ I. } & \multirow{3}{*}{ Technical } & Realization difficulties & $\mathbf{K}_{\text {UR }}^{\mathrm{T}_{\mathrm{R}}}$ & pt. & Decreasing & 5 & 5 & 3 \\
\hline & & $\begin{array}{c}\text { Degree of existing construction } \\
\text { load }\end{array}$ & $\mathbf{K}^{\mathrm{T}}$ SOIK & pt. & Decreasing & 3 & 3 & 5 \\
\hline & & $\begin{array}{l}\text { Architectural and construction } \\
\text { conditions }\end{array}$ & $\mathbf{K}^{\mathrm{T}} \mathrm{AB}_{3}$ & pt. & Increasing & 3 & 2 & 5 \\
\hline \multirow{3}{*}{ II. } & \multirow{3}{*}{ Economic } & Investment cost & $\mathbf{K}^{\mathrm{EK}} \mathrm{NI}$ & zł & Decreasing & 714290 & 781230 & 2433212 \\
\hline & & $\begin{array}{c}\text { Discounted payback period } \\
\text { (DPP) }\end{array}$ & $\mathbf{K}^{\mathrm{EK}}{ }_{\mathrm{DPP}}$ & years & Decreasing & 22.0 & 25.0 & none \\
\hline & & Net present value (NPV) & $\mathbf{K}^{\mathrm{EK}}{ }_{\mathrm{NPV}}$ & $\mathrm{zl}$ & Increasing & 91244 & 3558 & -3512070 \\
\hline \multirow{3}{*}{ III. } & \multirow{3}{*}{ Energy } & Amount of "produced" electricity & $\mathbf{K}^{\text {EN }}$ SRIPEE & $\mathrm{kWh} /$ year & Increasing & 107300 & 110278 & 50156 \\
\hline & & PV peak electric power for STC & $\mathbf{K}^{\mathrm{EN}_{\text {SME }}}$ & $\mathrm{kWp}$ & Increasing & 174.2 & 179.1 & 78.7 \\
\hline & & $\begin{array}{l}\text { Efficiency of conversion of the } \\
\text { module }\end{array}$ & $\mathbf{K}^{\mathrm{SS}_{\text {WSKM }}}$ & $\%$ & Increasing & 15.51 & 16.29 & 23.7 \\
\hline \multirow{3}{*}{ IV. } & \multirow{3}{*}{ Environmental } & $\begin{array}{c}\text { Rate of return of embedded } \\
\text { energy (EPBT) }\end{array}$ & $\mathbf{K}^{\mathrm{SS}} \mathrm{EPBT}$ & year & Decreasing & 8.30 & 13.70 & 11.00 \\
\hline & & Reduction of $\mathrm{CO}_{2}$ emission & $\mathbf{K}^{\mathrm{SS}}{ }_{\mathrm{REZ}}$ & tonnes & Increasing & 1321 & 874 & 520 \\
\hline & & Reduction of EP consumption & $K^{\text {EN }}$ SRRZEP & $\mathrm{kWh} /$ year & Increasing & 246791 & 253640 & 115360 \\
\hline
\end{tabular}

\section{Multi-criteria analysis}

As a multi-criteria decision support tool the analytical network process (ANP) has been employed. The detailed description of ANP method can be found in [3, 4]. ANP method is related to the AHP method, one of the best known and most widely used in the world $[5,6]$. The set of evaluation criteria (features) has an open character and is created in the dialog mode between the decision-maker and the expert - in the present case, an expert in planning the development of energy supply systems.

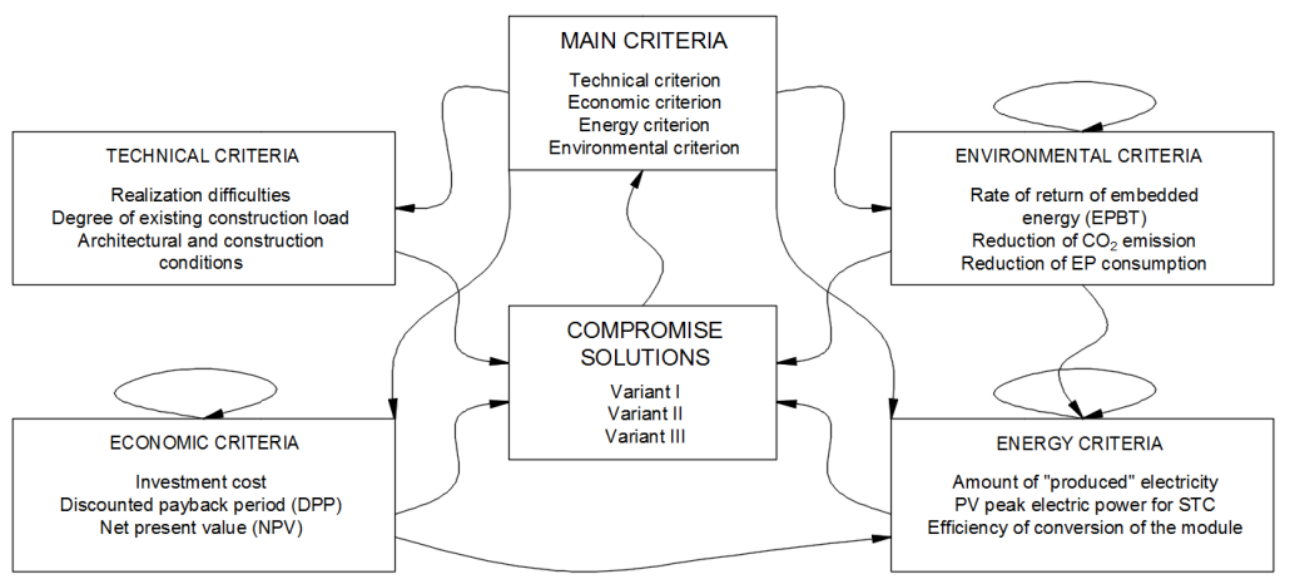

Fig. 7. The structure of the analytic network process (ANP) of defined decision problem.

\subsection{Determination of the decision-makers preference profiles}

The analysis of ANP for the evaluation of pairs of individual criteria, sub-criteria and variants in all specific relationships related to the decision-making network (Fig.7) includes the preference model of the decision maker - Investor. Pairwise comparisons are made with respect to all combinations of interconnections between the elements and their groups. The ANP method is based on a 9-level scale of comparison, analogous to the AHP method [3]. 


\subsection{Calculations}

The practical software that uses the ANP method is the Super Decisions (C) program [7]. The latter has been used in the calculations.

In accordance with the principles of the ANP method, after creating the decision-making network (Fig. 7), one has to determine the concentrations of elements and establish connections between them (Tab. 2). Super-matrixes are the fundamental tools used to structure the work in the ANP method. They represent preferences indicate an advantage of the elements on the left side of the matrix over elements located in the upper part. Preference vector "a" calculated from pairwise comparisons of the data elements defines the influence of another component element of the model. When the element has no effect on the other, the preference is not defined and shall be replaced by zero (Tab. 2).

Table 2. Super matrix defining the relationship between the components of the network structure

\begin{tabular}{|c|c|c|c|c|c|c|}
\hline Node label & Variants & $\begin{array}{c}\text { Main } \\
\text { criteria }\end{array}$ & $\begin{array}{c}\text { Technical } \\
\text { criteria }\end{array}$ & $\begin{array}{c}\text { Economical } \\
\text { criteria }\end{array}$ & $\begin{array}{c}\text { Energy } \\
\text { criteria }\end{array}$ & $\begin{array}{c}\text { Environmental } \\
\text { criteria }\end{array}$ \\
\hline Variants & 0 & 1 & 0 & 0 & 0 & 0 \\
\hline Main criteria & 1 & 0 & 0 & 0 & 0 & 0 \\
\hline Technical criteria & 0 & 0.121509 & 0 & 0 & 0 & 0 \\
\hline Economical criteria & 0 & 0.389051 & 0 & 0.142857 & 0 & 0 \\
\hline Energy criteria & 0 & 0.172403 & 0 & 0.142857 & 0.166667 & 0.280833 \\
\hline Environmental criteria & 0 & 0.317036 & 0 & 0 & 0 & 0.13501 \\
\hline
\end{tabular}

The preferences vectors are calculated successively and then introduced in the columns of unweighted network decision-making super-matrix. The essence of the ANP method is a synthesis and presentation of the final results in the form of priorities for all possible dependencies, and coupling cycles between network elements. The result is the creation of super-matrix' limits, comprising the final preference of each element of the model over the other elements.

\subsection{Calculation results}

The final result of conducted calculations is a ranking of variants (Tab. 4). The "raw" column presents the results derived from super-matrix limits (Tab. 3), the "normalized" column contains the normalized values of super-matrix limits, whereas the "target" column accounts for the values relative for all the variants considered.

Table 4. The results of the analysis of the ANP for the defined decision problem

\begin{tabular}{|c|c|c|c|}
\hline & Target & Normalized & Raw \\
\hline Variant I & $\mathbf{1 . 0 0 0 0 0 0}$ & 0.444702 & 0.138158 \\
\hline Variant II & $\mathbf{0 . 7 9 6 7 1 7}$ & 0.354302 & 0.110073 \\
\hline Variant III & $\mathbf{0 . 4 5 1 9 8 0}$ & 0.200996 & 0.062444 \\
\hline
\end{tabular}

The results of the calculations indicate that the most compromise way of energy supply to the analyzed building with the use of a photovoltaic system is the realization of Variant I.

The highest priority (Tab. 3) among the main criteria has the economic criterion (0.12087), followed by: environmental criterion (0.09849), the energy criterion (0.05356) and technical criterion (0.03775). The most important sub-criteria are capital expenditures (0.07051), the amount of "produced" electricity (0.06025) and the rate of return of embedded energy - EPBT (0.0486). Sub-criteria with the least significance are: degree of existing construction load (0.00593), realization difficulties (0.00941) and the efficiency of conversion of the module (0.01501). 
Table 3. Date from the super matrix limits defined decision problem

\begin{tabular}{|c|c|}
\hline Compromise solutions & Priority \\
\hline Variant I & $\mathbf{0 . 1 3 8 1 6}$ \\
\hline Variant II & 0.11007 \\
\hline Variant III & 0.06244 \\
\hline
\end{tabular}

\begin{tabular}{|c|c|}
\hline Sub-criteria & Priority \\
\hline Realization difficulties & 0.00941 \\
\hline Degree of existing construction load & 0.00593 \\
\hline Architectural and construction conditions & 0.02241 \\
\hline Investment cost & $\mathbf{0 . 0 7 0 5 1}$ \\
\hline Discounted payback period (DPP) & 0.03022 \\
\hline Net present value (NPV) & 0.03022 \\
\hline Amount of "produced" electricity & $\mathbf{0 . 0 6 0 2 5}$ \\
\hline PV peak electric power for STC & 0.03207 \\
\hline Efficiency of conversion of the module & 0.01501 \\
\hline Rate of return of embedded energy (EPBT) & $\mathbf{0 . 0 4 8 6 0}$ \\
\hline Reduction of $\mathrm{CO}_{2}$ emission & 0.02342 \\
\hline Reduction of $\mathrm{EP}$ consumption & 0.03061 \\
\hline
\end{tabular}

\subsection{Discussion of calculations results}

The results of multi-criteria analysis leads to the following conclusions:

- variants I and II demonstrate the best economic performances over the long time period taken into consideration (25 years),

- the investment cost and the amount of electricity produced in the PV panels are determinants of a favourable outcome for those variants,

- the sub-criterion related to the amount of solar energy converted to electricity directly affects all environmental sub-criteria: EPBT, reduction of $\mathrm{CO} 2$ emission and reduction of EP consumption,

- the Sub-criterion for PV peak electric power affect the investment cost and the amount of converted energy,

- variant III based on transparent PV panels has the lowest rank and should be excluded from further analysis.

\section{Summary}

The choice of the electricity supply system for the public buildings with the use of PV installations should be treated as a decision problem due to its complexity. It can be solved using multi-criteria aid methods and this paper presents a new approach to the conceptual design phase of such systems. The proposed multi-criteria analysis performed using the method of analytical network process (ANP) and the calculation program Super Decisions (C) has proven to be an effective tool for energy planning, leading to indications for the recommended variant of PV panels based electricity supply system for public buildings. The proposed approach has been employed in the context of a case study analysis - the choice of PV panels based electricity supply system for an educational buildings located in the city of Poznan, Poland. The technical, economic, energy and environmental criterion are the four main decision criteria that have been identified as most relevant for the defined decision problem. The proposed set of main criteria and sub-criteria has an open character and can be subject to changes in the process of modelling the preferences of the decision maker. 


\section{References}

1. J. Bernal-Agustin, R. Dufo-Lopez, Renew Energ, 6 (2006)

2. K. P. Bhandari, J.M. Collier, R.J. Ellingson, D.S. Apul, Renew Sust Energ Rev, 47, 133 (2015)

3. T.L. Saaty, Encyclopedia of Operations Research and Management Science (Springer US, 2001)

4. T.L. Saaty, Decision Making with Dependence and Feedback The Analytic Network Process, (RWS Publications, 1994)

5. B. Radomski, T.M. Mróz, W. Grządzielski, COW, 47/2, 47 (2016)

6. W. Grządzielski, T.M. Mróz, B. Radomski, Trans. IFFM (to be published)

7. http://www.superdecisions.com/ 